\title{
Immigrant Diversity and Complex Problem Solving
}

\author{
by
}

\author{
Abigail Cooke \\ University at Buffalo, SUNY \\ Thomas Kemeny \\ University of Southampton
}

The research program of the Center for Economic Studies (CES) produces a wide range of economic analyses to improve the statistical programs of the U.S. Census Bureau. Many of these analyses take the form of CES research papers. The papers have not undergone the review accorded Census Bureau publications and no endorsement should be inferred. Any opinions and conclusions expressed herein are those of the author(s) and do not necessarily represent the views of the U.S. Census Bureau. All results have been reviewed to ensure that no confidential information is disclosed. Republication in whole or part must be cleared with the authors.

To obtain information about the series, see www.census.gov/ces or contact Fariha Kamal, Editor, Discussion Papers, U.S. Census Bureau, Center for Economic Studies 2K132B, 4600 Silver Hill Road, Washington, DC 20233, CES.Papers.List@census.gov. To subscribe to the series, please click here. 


\begin{abstract}
In the growing literature exploring the links between immigrant diversity and worker productivity, recent evidence strongly suggests that diversity generates productivity improvements. However, even the most careful extant empirical work remains at some remove from the mechanisms that theory says underlie this relationship: interpersonal interaction in the service of complex problem solving. This paper aims to 'stress-test' these theoretical foundations, by observing how the relationship between diversity and productivity varies across workers differently engaged in complex problem solving and interaction. Using a uniquely comprehensive matched employer-employee dataset for the United States between 1991 and 2008, this paper shows that growing immigrant diversity inside cities and workplaces offers much stronger benefits for workers intensively engaged in various forms of complex problem solving, including tasks involving high levels of innovation, creativity, and STEM. Moreover, such effects are considerably stronger for those whose work requires high levels of both problem solving and interaction.
\end{abstract}

Keyword: immigration, diversity, complex problem solving, spillovers, productivity, human capital

\footnotetext{
* This work was produced while the authors were Special Sworn Status researchers at the U.S. Census Bureau's Center for Economic Studies. Any opinions and conclusions expressed herein are those of the authors and do not necessarily represent the views of the U.S. Census Bureau. All results have been reviewed to ensure that no con dential information is disclosed.
} 


\section{Introduction}

Researchers in a wide range of disciplines contend that people born in different locations carry with them different perspectives, and that the combination of these perspectives, whether in an organization, city, or other context, can generate economic advantages. These advantages are said to arise because diverse groups are collectively able to map out a wider range of approaches and solutions to complex problems. Of course, heterogeneity is not unambiguously beneficial. People from diverse backgrounds may find it hard to find common ground, and this will raise the costs of interacting, and thereby inhibit productivity.

To the extent that such mechanisms operate in the economy, we can think of 'immigrant' or 'birthplace' diversity as a public good, generating advantages or disadvantages that are not fully captured by individuals. Studies exploring this idea inside individual organizations find mixed results. At the metropolitan scale, across a variety of country contexts and time periods, researchers find suggestive evidence that immigrant diversity exerts an independent positive influence on productivity (Ottaviano and Peri, 2006; Nathan, 2011; Kemeny, 2012; Bellini et al., 2013; Trax et al., 2012; Suedekum et al., 2014; Kemeny and Cooke, 2015). Still, existing studies remain at some remove from the hypothesized microfoundations, mostly because complex problem solving and interactions in diverse groups are hard to observe, especially at scale.

This paper aims to more closely connect available evidence to these microfoundations. It extends knowledge by exploring the idea that the productivity benefits from urban and workplace-specific immigrant diversity will vary according to the kind of activities in which workers are engaged. Theory suggests two under-explored considerations. First, according to Hong and Page (2001), Weber and Fujita (2004) and others, benefits from diversity ought to be amplified in activities that are challenging, knowledge-intensive, innovationoriented, and lacking in pre-established routines - activities that we will henceforth describe using the shorthand 'complex problem solving.' Second, given that spillovers are generated through interpersonal interaction, workers in such activities that intensively require social engagement should benefit more strongly from the diversity that surrounds them. To take an extreme example, contrast a sculptor's job, which intensively demands 
one aspect of complex problem solving - creativity - but does not necessarily require a great deal of interpersonal interaction, with that of a Hollywood movie director, where success depends on both. If the mechanisms shaping diversity's relationship to productivity are in fact rooted in the interaction of heuristics and the concomitant benefits to problem solving, then diversity effects ought to matter more for the movie director than the solitary scuptor.

Data on U.S. workers, employers, industries, and occupations are used to test these ideas. Our primary data source is the U.S. Census Bureau's confidential Longitudinal Employer-Household Dynamics (LEHD) data. LEHD provides a uniquely comprehensive matched employer-employee dataset describing workers and their work establishments, available between 1991 and 2008. Among other things, LEHD describes workers' place of birth, and permits description of changes in productivity as measured by their wages. To capture variation in complex problem solving and interaction, we combine data from two sources. The Bureau of Labor Statistics' Occupational Employment Statistics (BLS OES) provides detailed information on the occupational structure of industries. And the U.S. Department of Labor's O*NET database captures many facets of the task content of specific jobs. By combining the occupation-specific task characteristics with the occupational structure of industries, we produce a set of measures capturing the intensity of complex problem solving in each industry.

Grouping workers according to the task characteristics of their industry, we predict how their wages change in response to changes in the diversity found in their city and workplace. Models are estimated over multi-year job 'spells', within which workers remain in a single establishment and city. This permits fixed effects estimation, allowing us to absorb stationary unobserved heterogeneity for individuals, their workplaces, and their metropolitan areas. LEHD also offers an additional advantage: it enables us to measure diversity not just in cities but also in establishments. In this manner it is possible to better identify the specific contexts where any productivity-enhancing or -inhibiting effects may reside.

We find broad support for the theory underlying this growing body of work. Workers in industries that intensively demand complex problem solving benefit from substantial and statistically significant increases in wages in the face of increased city diversity. Workers 
in industries that require little complex problem solving experience no statistically significant wage impacts from diversity. Additionally, as theory predicts, among those workers employed in industries that privilege complex problem solving, those that are additionally intensive in interpersonal interaction gain particularly large rewards from increases in diversity. Responses to changes in workplace immigrant diversity differ somewhat: diversity remains positive and significantly related to productivity across the complex problem solving spectrum, but workers in industries that feature high levels of complex problem solving enjoy benefits from diversity that are twice as large as their counterparts in activities where complex problem solving is not particularly important. Overall, these disparate effects of diversity, depending on the work characteristics, match theoretical expectations and lend strong support that the theory motivating the growing diversity-productivity literature indeed explains the empirical relationships observed.

\section{Literature}

The idea that a city with a diverse group of immigrants might outperform one in which individuals are more homogeneous finds it chief motivation at the intersection of two bodies of work: one exploring the consequences of diversity in organizations; the other examining subnational regions as sites of diversity-induced external economies.

From the longstanding scholarship on the impacts of heterogeneity in organizations comes the main theoretical logic for an economic impact of immigrant diversity. The initial premise is that observable demographic characteristics are related to underlying cognitive regularities (Nisbett et al., 1980; Clearwater et al., 1991; Thomas and Ely, 1996; Hong and Page, 2001). Hong and Page (2004), for example consider that individuals with 'identity diversity,' defined as those with particular demographic, geographic, ethnic, or cultural backgrounds, are also likely to be distinctive in terms of their 'functional diversity,' meaning the ways they perceive and solve problems. Some hold that this functional diversity can improve economic performance, while others contend it ought to reduce it. On the positive side, it is argued that more functionally-diverse organizations ought to be more productive for two reasons. First, when faced with a problem or challenge, they will be able to access a larger range of potential solutions, and should thereby be able 
to select the one that will be most effective. Second, they ought to be able to crosspollinate to generate new solutions that cannot be reduced to any one perspective (Aiken and Hage, 1971). Computational models of this idea provide support, by showing that groups composed of diverse problem solvers can outperform teams made up of agents with superior but more homogeneous abilities (Huberman, 1990; Hong and Page, 2004). More recently, other potential channels have been offered for these positive impacts, including facilitation of information transfer and connections to external partners and markets (see review in Nathan, 2014).

Arguments suggesting that diversity will negatively impact performance flow from psychology's 'social identity theory.' According to this view, diverse organizations will tend toward internal fragmentation, with rent-seeking behavior and raised costs of cooperation across the fragments (Tajfel, 1974; Turner et al., 1987; Van Knippenberg and Schippers, 2007; Harrison and Klein, 2007). It is worth noting that, while these streams of organizational research make different predictions, they posit fundamentally compatible visions of the mechanisms by which diversity influences economic outcomes. Whether diversity helps or hurts, its economic effects flow from interpersonal interactions among individuals who are demographically, and therefore cognitively different. One side emphasizes the costs associated with such interactions when problem solving is needed, while the other side stresses the benefits.

Urban-focused researchers have built upon this foundation, suggesting that the publicgood (or bad) qualities ascribed to diversity in the workplace may equally be in operation at higher spatial scales. This flows from a larger body of theory and empirics making the point that regional economies offer positive externalities - economic benefits that are a function of scale but that cannot be fully captured by individual agents (Feldman and Audretsch, 1999; Fujita and Thisse, 2013). Among the most important of these externalities is thought to flow from accumulations of human capital, such that being surrounded by concentrations of well-educated and highly-skilled workers is believed to enhance one's own productivity. In this vein, one can consider diversity to engender a specific kind of geographically-bounded social return to human capital. Similar to the wealth of studies indicating local spillovers from education (for instance: Rauch, 1993; Moretti, 2004a,b), the present paper and ones like it explore local spillovers from immigrant 
diversity.

A growing body of empirical work has sought to investigate such local spillovers. The seminal reference is Ottaviano and Peri (2006), who take a spatial equilibrium approach, jointly testing the links between diversity and wages and rents across U.S. metropolitan areas. They find that birthplace diversity is positively and robustly correlated with both wages and rents, indicating that diversity chiefly acts to raise productivity. Similar tests, in other advanced economies, across different time periods, and sometimes using various means of capturing amenities and productivity, similarly find a positive relationship suggesting that diversity has a positive influence on productivity (Nathan, 2011; Kemeny, 2012; Trax et al., 2012; Bellini et al., 2013; Bakens et al., 2013; Longhi, 2013; Ager and Brückner, 2013; Suedekum et al., 2014). ${ }^{1}$ Recent work has gone deeper by addressing lingering concerns about bias engendered by problems of endogeneity arising from unaccounted for sorting behavior and reverse causality; researchers have also begun to consider whether urban diversity effects remain after accounting for diversity in the workplace (Trax et al., 2012; Kemeny and Cooke, 2015; Nathan, 2015; Østergaard and Timmermans, 2015). Studies addressing some or all of these issues continue to find a positive association between diversity and productivity at both metropolitan and workplace scales. Despite stronger econometrics, however, we remain at some remove from the microfoundations that are said to underlie the relationship of interest. Complex problem solving and the interpersonal interactions upon which it depends are hard to observe, particularly at scale, and as a result, studies are forced to merely assume that any good or bad outcomes are driven by these latent phenomena.

Our paper takes the first steps toward addressing this problem, by considering how this diversity-productivity relationship might be more or less important across specific kinds of activities. Theory suggests looking in two places: in activities that are rich in complexproblem solving, and in those that intensively require interaction. To the extent that innovation is a product of both problem solving and interaction, it is worth mentioning studies exploring the links between diversity (variously defined) and innovation in organizations (Watson et al., 1993; Auh and Menguc, 2005; Talke et al., 2010; Østergaard et al.,

\footnotetext{
${ }^{1}$ For a detailed review of the empirical literature on the productivity implications of urban immigrant diversity, see Kemeny (2014).
} 
2011; Faems and Subramanian, 2013; Ozgen et al., 2013a; Ibert and Müller, 2015; Nathan, 2014; Parrotta et al., 2014), and in regional economies (Maré et al., 2014; Gagliardi, 2014; Lee, 2014). This work mostly finds that firms and regions that feature higher levels of diversity tend to out-innovate their less diverse peers. Still, such studies are narrow in the sense that they focus on innovation, rather than complex problem solving more broadly. More importantly, since innovation is the outcome of choice, these studies do not directly consider how differences in the demands for interaction and complex solving moderate the observed links between diversity and performance. In short, as compared with the regional literature, they remain at more or less the same distance from hypothesized mechanisms. ${ }^{2}$

The aim of this paper is to add to our knowledge by shedding light on the mechanisms that are theorized to explain the observed relationship between immigrant diversity and productivity. In seeking to 'stress-test' the accepted explanations, we consider the following hypotheses:

1. The positive effects of city and workplace diversity on productivity will be stronger for workers in industries that intensively require complex problem solving.

2. The positive effects of city and workplace diversity on productivity will be especially strong for workers in industries that require high levels of both interaction and complex problem solving.

\section{Empirical Approach}

The basic source of identification in this paper consists of comparing two groups of individuals in terms of how their work activities shape the relationship between diversity and productivity. To capture the relationship between diversity and productivity, we adapt an approach used by Moretti (2004a) and Gibbons et al. (2013) in studies on local educational spillovers. Out of the set of all available workers, we estimate our relationship of interest only on spells of 'stayers' - individuals that remain in their work establishment

\footnotetext{
${ }^{2}$ In this light, our study is most closely related to Parrotta et al. (2014). Though it is aimed at diversity defined along ethnic lines, and only within firms, the authors do consider how diversity among blue- and white-collar workers may differently influence innovation, on the basis that the latter group is more likely to engage in complex problem solving. They confirm strongly differentiated effects. They also consider communication costs, showing that diversity that brings with it linguistic divides offers weaker innovationaugmenting effects.
} 
(and thus metropolitan area) for at least two years. As these workers are fixed in place, one important source of variation comes from the panel structure of the data, and more specifically from the shifts around these workers in the composition of the cities in which they live, and the establishments in which they work. In short, by observing the same individual in the same firm and city across time, we control for unobserved permanent individual, establishment, and city heterogeneity. The general approach is represented in the following equation:

$$
\ln (w)_{i p j t}=d_{j t} \beta++d_{p j t} \gamma+X_{i p j t}^{\prime} \delta+E_{p j t}^{\prime} \theta+C_{j t}^{\prime}+\mu_{i t}+\eta_{t}+\nu_{i p j t}
$$

where, $\ln (w)$ represents the $\log$ annual wages of an individual worker $i$ in establishment $p$ located in metropolitan area $j$ at time $t ; d_{j t}$, a key independent variable of interest, measures city-specific immigrant diversity, while $d_{p j t}$ measures diversity at the level of the establishment; $X^{\prime}$ represents time-varying worker characteristics; $E^{\prime}$ describes a vector of dynamic employer characteristics; and $C^{\prime}$ indicates time-varying city-specific characteristics. Of particular importance is $\mu_{i p j}$, our individual-establishment-city fixed effect, which simultaneously accounts for bias arising due to variation in permanent but potentially unobserved characteristics of individual workers, the establishments where they work, and the regional economies in which they live. At the individual level, such pertinent stationary unobserved heterogeneity could arise due to differences in such characteristics as innate ability, intelligence, or motivation. Among establishments, it could be driven by differences in such features as capital intensiveness or product quality. And at the level of metropolitan regions, differences in specialization, agglomeration, and other factors could be relevant, if hard to observe. Of the remainder of Equation (1), $\eta_{t}$ represents unobserved time-specific shocks that exert uniform impacts across all individuals, such as the business cycle; $\nu_{i p j t}$ is the standard error term.

More generally, applying the fixed effects estimator, Equation (1) explores how an individual's productivity responds to changes in the level of immigrant diversity present in her metropolitan area, while it accounts for the major sources of spurious correlation that might bias estimates of the impact of diversity on wages produced using the standard approach. As in Acemoglu and Angrist (2001) and Moretti (2004a), we argue that 
identification does not require a complementary equation predicting rents, since for regions that contain producers selling tradable goods, wages unadjusted for cost-of-living difference will reflect underlying productivity, as such firms face national, not local prices. The main identifying assumption to be satisfied is that the return on unobserved worker ability in their establishment and city is stationary over time, or at least that changes are uncorrelated with changes in city-specific diversity. As in Moretti (2004a), this return need not be general across higher-order categories, in this case establishments and cities.

Sketching out our analytical approach in more detail, we address our two hypotheses in turn. We first estimate Equation (1) separately for workers who we classify as being at high and low levels of complex problem solving. Hypothesis (1) suggests that coefficients on our measures of diversity ought to be larger among the group of workers engaged in complex problem solving. Next, among those workers with high levels of complex problem solving, we estimate Equation (1) separately for those with low and high levels of interaction our sculptors and movie directors. Hypothesis (2) suggests that coefficients for diversity will be comparatively higher among workers in activities that demand high levels of both complex problem solving and interaction.

\section{Data}

\subsection{Building Diversity Measures and the Main Analytical Sample}

To estimate Equation (1), we use data from the U.S. Census Bureau's confidential Longitudinal Employer-Household Dynamics (LEHD) Infrastructure files. The LEHD program integrates administrative records from state-specific unemployment insurance (UI) programs with Census Bureau economic and demographic data, providing a nearly universal picture of jobs in the United States (McKinney and Vilhuber, 2011). The version of the data available for this study covers 29 states between 1991 and $2008 .{ }^{3}$ Within those states, our sample is limited to jobs occurring in the set of 163 Metropolitan Core-Based Statistical Areas (CBSAs) which do not cross state borders with a state unavailable in the raw data, ensuring that we observe all workers throughout each analyzed CBSA.

\footnotetext{
${ }^{3}$ States used in our project: AR, CA, CO, FL, GA, HI, IA, ID, IL, IN, LA, MD, ME, MT, NC, NJ, NM, NV, OK, OR, SC, TN, TX, UT, VA, VT, WA, WI, WV.
} 
Assembling the core analytical sample involves two major steps. The first is to estimate annual immigrant diversity for the sample of CBSAs, as well as for the work establishments operating within them. The second key task is to assemble the sample of workers from which to estimate our relationships of interest.

To create city-specific measures of diversity, we observe each working-age individual's job spell with each employer, and by implication, each employee's city of work at a given quarter. We use this information, in combination with LEHD's record of each worker's country of birth, to estimate a CBSA-specific measure of immigrant diversity based on the set of all workers in the city during a given calendar year. To do so, we follow standard practice by estimating a fractionalization index:

$$
\text { Fractionalization }_{j t}=1-\sum_{r=1}^{R} s_{j t r}^{2}
$$

where $s$ is the proportion of residents in city $j$ and time t who were born in country $r$; and $R$ is the number of different countries represented among residents of that city. The index nears zero as diversity decreases and its maximum value approaches one as heterogeneity increases; it is commonly described as measuring the probability that two randomly-drawn individuals in a location were born in different countries. The pervasiveness of this measure in diversity research is no doubt related to the simple and intuitive manner by which it captures the breadth of countries from which individuals originate, as well as the sizes of these different country groups in a given city. ${ }^{4}$

Birthplace fractionalization is constructed analogously for workplaces, based on the set of coworkers in each establishment and year. One difference between the city and establishment measures is that instead of weighting each person's contribution to birthplace diversity evenly (as we do in the city measures), we weight each person's contribution depending on how many quarters they work in a particular establishment. If they worked half the year in one establishment and half the year in another, then they count as half a person in the diversity measures of each establishment for that year. The resulting annual

\footnotetext{
${ }^{4}$ Fractionalization indices of this kind have been used to capture a wide variety of categorical forms of diversity, including language, birthplace, race and ethnicity (see, for example, Taylor and Hudson, 1972; Easterly and Levine, 1997; Knack and Keefer, 1997; Ottaviano and Peri, 2006; Sparber, 2010). Other ways of measuring diversity have been proposed (Ozgen et al., 2013b; Kemeny, 2014), and explored empirically in relation to wages (see Kemeny and Cooke, 2015), with results that did not materially depart from those gained using the fractionalization index.
} 
diversity measures at the CBSA and workplace levels provide key independent variables of interest in our models.

To build the main analytical sample of workers, we start from the same initial sample of workers in establishments and cities. Regarding these workers, LEHD provides a range of salient characteristics: place of birth, selected demographic characteristics (gender, birth year, race), and the quarterly wages earned. LEHD also offers data specific to each establishment, such as their location, total annual employment, and best six-digit NAICS industry code. Our models relate annual changes in wages with changes in the city and workplace diversity. To accomplish this we focus on people who remain in a single city and in a single establishment as others move in and out of both, changing the level of diversity around the stayers. For each worker, we track only their longest job spell in any city in our sample, so an individual only shows up in one establishment and one city in the panel, even if they have multiple job spells over their observed career that meet the two-year minimum. Thus, our analytical sample includes many fewer people than those who contributed to the city and establishment diversity measures. Specifically, our analytical sample is a panel of individual workers, tracking their wages in a single job spell of at least two continuous years in a single establishment. Our analytical sample is further reduced because, in keeping with the literature, we drop workers with extremely low wages. And we drop workers who are simultaneously employed in multiple jobs, so that we can clearly identify the source of any establishment-specific diversity effects. To ensure that our measure of workplace diversity is sensible, we also restrict the sample to jobs at establishments with at least ten employees.

\subsection{Measuring Complex Problem Solving and Interaction in Work Ac- tivities}

Our empirical strategy relies on differentiating individuals based on the kinds of work activities in which they are engaged. LEHD does not classify workers on the basis of their occupation, but it does offer detailed information about the industry in which their establishment is involved. We use this information to capture variation in complex problem solving and interaction.

To do so, we start from the Department of Labor's O*NET database, which provides 
rich information on the task characteristics involved in different occupations. From the dozens of variables available for each occupation, we select the following that triangulate on the latent concept of complex problem solving: (1) creativity, (2) innovation, (3) complex problem solving, (4) educational requirements (schooling), (5) science, (6) engineering \& technology, and (7) mathematical reasoning. Additionally, we use a measure of the 'social orientation' of workers in each occupation as a proxy for the intensity of interaction. Each of these variables provides an occupation-specific score indicating the intensiveness with which it is required in a particular kind of job. We then combine these data with occupation-by-industry employment estimates from the Bureau of Labor Statistics' Occupational Employment Statistics (OES), in order to arrive at industry-specific measures of the various indicators for complex problem solving and interaction. Specifically, for each task characteristic, we calculate the weighted sum of all occupations' scores, where the weight is the proportion of total 4-digit NAICS industry employment a particular occupation represents. This results in a series of measures, each capturing some aspect of the underlying concepts of complex problem solving and interaction. Finally, for each measure, each of nearly 300 industries is assigned to a tercile. Equation (1) is then estimated on workers in industries in the highest, and separately, the lowest terciles. ${ }^{5}$

Table 1 provides some evidence on the usefulness of this approach. It describes the five highest and lowest scoring industries using the 'importance of complex problem solving' measure in $\mathrm{O}^{*} \mathrm{NET}$. The table shows that those industries ranked most intensive in complex problem solving conform to general intuitions, embodying highly technological- and knowledge-intensive activities. Meanwhile, at the bottom of the list are routine, low-skill retail activities and mail delivery.

It is our belief that complex problem solving is multifaceted, and hence we attempt to triangulate by using different indicators. Table 2 describes correlations among these different measures of the deeper latent concept. It demonstrates that, while there is considerable overlap among these measures, they are not capturing precisely the same kinds of activities. The highest correlation is between innovation and creativity, with a

\footnotetext{
${ }^{5}$ We use the 2008 OES data to capture employment by occupation and industry. While there are likely some changes in the occupational structure of certain industries between 1991 and 2008, our analytical strategy of comparing the extremes (highest versus lowest tercile of each measure) makes any restructuring unlikely to matter substantially.
} 
Table 1: Top Five Highest and Lowest Industries in Terms of Complex Problem Solving

\begin{tabular}{llc}
\hline Rank & Industry & Standardized Score \\
\hline 1 & Computer Systems Design and Related Services & 0.681 \\
2 & Software Publishers & 0.672 \\
3 & Computer and Peripheral Equipment Manufacturing & 0.638 \\
4 & Architectural, Engineering, and Related Services & 0.617 \\
5 & Scientific Research and Development Services & 0.602 \\
$\ldots$ & & \\
287 & Clothing Stores & 0.261 \\
288 & Shoe Stores & 0.257 \\
289 & Postal Service & 0.250 \\
290 & Consumer Goods Rental & 0.219 \\
291 & Health and Personal Care Stores & 0.169 \\
\hline Note: Authors' calculations, based on 'complex problem solving importance' variable from O*NET
\end{tabular}

value of nearly 0.9 . We believe that the shape of these relationships supports our approach. Specifically, should we produce consistent results across each of these measures, we can be more confident in relating these results to the underlying latent concept.

\subsection{Sample characteristics and control variables}

Table 3 provides summary statistics for the analytical sample. It includes nearly 29 million individual workers working in over one million establishments, and despite the selective requirements for inclusion in the sample, it shares the broad characteristics of the US urban labor force. The primary outcome of interest is the change in individuals' annual earnings, measured in log form. Average annual earnings in the analytical sample are just over $\$ 35,000$. Given a fixed effects approach, other available individual-level variables, such as gender or race, drop out in estimation because they are not time varying; these are included in Table 3 to better describe the sample. The average age of the workers is just over 40 years old and the average job spell is just under five years. At the establishment level, besides birthplace diversity, we also include workplace employment in the models, since workforce size can influence productivity. In the sample, the average establishment has 64 employees. At the city level, birthplace diversity is the chief variable of interest, however we also include controls for other localized externalities. CBSA employment (average 472,000 workers), sourced from the Bureau of Economic Analysis, is included to capture the effect of agglomeration economies. To control for educational spillovers, we 


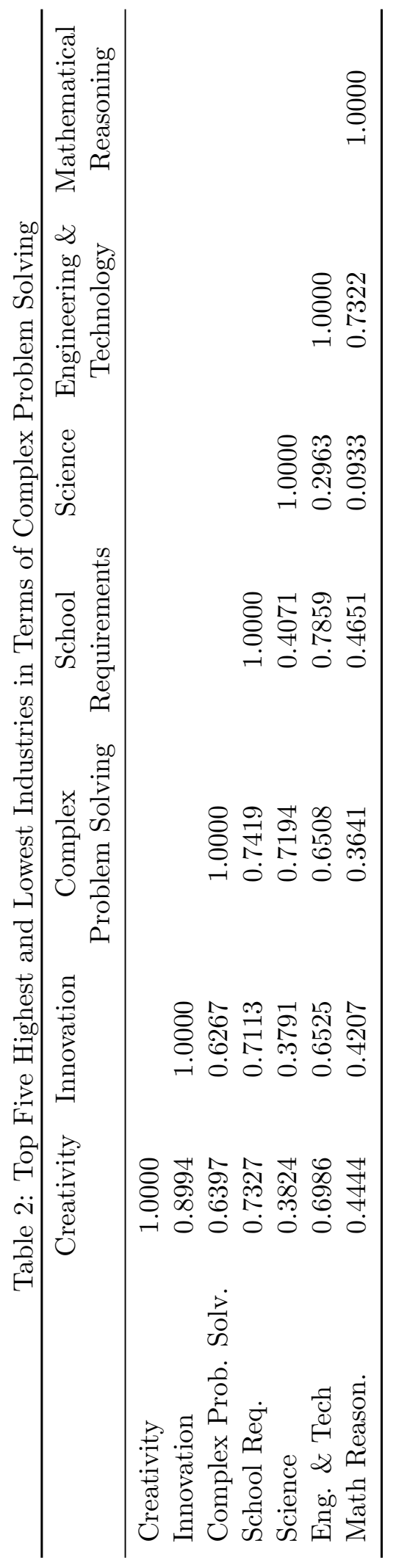


include the annual share of each CBSA's workforce holding at least a 4-year college degree, using 5\% public-use IPUMS extracts from the 1990 and 2000 Decennial Censuses, as well as 1\% samples for each year of the 2001-2008 American Community Survey (Ruggles et al., 2010). ${ }^{6}$ In the average city in our sample, about $26 \%$ of the labor force has a college education.

Table 3: Summary Statistics

\begin{tabular}{llc}
\hline Variable & Mean & Standard Deviation \\
\hline Individual Characteristics & & \\
Log Annual Earnings & 10.47 & 0.65 \\
Age & 40.23 & 11.72 \\
$\quad$ Spell Duration & 4.92 & 3.27 \\
Establishment Characteristics & & \\
$\quad$ Birthplace Fractionalization & 0.219 & 0.205 \\
Foreign-Born & 0.058 & 0.143 \\
Employment & 64.01 & 284.33 \\
City Characteristics & & \\
Birthplace Fractionalization & 0.180 & 0.129 \\
College Share, All Workers & 0.257 & 0.074 \\
Employment (10,000s) & 47.20 & 88.34 \\
Share Foreign-Born & 0.102 & 0.084 \\
\hline Individuals & 28950000 & \\
Establishments & 1026000 & \\
CBSAs & 163 & \\
\hline
\end{tabular}

\section{Results}

This section presents results from a series of models estimating variants of Equation (1), which seeks to describe the relationship between immigrant diversity and worker productivity. The chief aim is to identify potential contrasts in this relationship between workers engaged in different kinds of activities. Specifically, we explore how diversity may differently impact workers engaged in high and low levels of complex problem solving. Within the subset of workers solving complex problems, we additionally explore differential impacts on the basis of the intensity of interpersonal interaction.

\footnotetext{
${ }^{6}$ We use available data to interpolate across absent years (1991-1999) as in Moretti (2004b). Our measure of education is sourced in this way despite having annual, individual-level imputed values of schooling attainment available in LEHD, since we found that the latter are only moderately correlated $(<0.4)$ with the more reliable values drawn from the Decennial and ACS.
} 
As discussed in the previous section, we are able to capture changes in diversity at both the city and the workplace scale. We expect that interactions in a workplace ought to reflect the kinds of characteristics found in the industry in which it operates. For instance, an industry like computer programming that intensively requires complex problem solving will mechanically feature firms (and by extension establishments) in which complex problem solving represents an important aspect of workplace interactions. Therefore, in establishments in such industries, we expect diversity to be especially important, as compared to establishments in industries where complex problem solving is relatively peripheral.

The interpretation of potential task-specific city effects is more complex. One possibility is that such effects represent interactions that are directly about work, but of an extra-establishment nature, in the manner of Marshall's (1890) localization economies. These could be interactions that occur across establishments within a multi-unit firm; between a firm and external buyers and suppliers or partners; or merely workplaces linked through other more informal interactions. Alternately (or additionally), any observed city-level diversity effects could represent a looser kind of interaction, in the manner of Jane Jacobs' sidewalk ballet. In such a case, we need to believe that one's industry shapes orientation to one's environment, such that a worker in industry $\mathrm{X}$ will derive from the sidewalk ballet different productivity benefits from than a worker in industry Y. Whichever route, we expect changes in city diversity to differentially influence worker productivity on the basis of that worker's industry. Given the absence of well-specified theoretical priors regarding the relative importance of these channels, we leave all options open.

\subsection{Main Estimates}

Table 4 presents the main estimates of the relationship between birthplace diversity and wages for workers across industries that are marked by low and high intensities of complex problem solving, variously defined. As described above, results are produced using fixed effects models on an annual panel of workers over their longest job spell during the study period (1991-2008). Each model includes a fixed effect that simultaneously absorbs unobserved heterogeneity at multiple levels: individual worker, establishment, and city. The estimated equations also include year fixed effects, capturing unmeasured, time-varying 
shocks that are uniform across workers, establishments, and cities. In Table 4, as well as in each of the proceeding tables of results, city-specific coefficients are listed first, with establishment-level coefficients following thereafter.

The first two columns of Table 4 explore the association between diversity and wages, using creativity as a proxy for complex problem solving. Column 1 estimates this relationship for workers in industries in the bottom tercile of creative intensity. It shows that workers in the least-creative industries are unaffected by changes in immigrant diversity in the city in which they live. The measure of educational spillovers - college share of the city labor force - is similarly not significant for these workers, though the size of the total labor force has a small, positive, and significant coefficient. The coefficient on establishmentlevel diversity is positive and significant, suggesting that, even among these workers, a rise in the immigrant diversity of one's co-workers exerts a positive influence on one's wages. The coefficient for establishment-level employment is as expected: small, positive, and significant. Column 2 shows results for workers in the most creativity-intensive sectors. For these high-creativity workers, changes in city immigrant diversity are positively and significantly related to wages. The control variables act as expected. City college share and employment are both positively related to wages. Establishment immigrant diversity is positively and significantly related to wages, but with a coefficient that is approximately double that estimated for the least creative workers.

Thus, depending on the tasks in which a worker is engaged, changes in immigrant diversity in one's city and workplace can either raise productivity or leave it unaffected. The typical worker in a low-creativity industry receives no spillovers from the immigrant diversity found in their city, and only a modest benefit from the diversity in their workplace. Meanwhile, an average worker in an industry in the top tercile of creativity receives considerable diversity spillovers at both scales: more than a $6 \%$ rise in wages for a one standard deviation increase in cities, and a $2.2 \%$ rise with a similar increase in diversity in their establishment.

The remainder of Table 4 considers relationships of this kind for additional proxies for complex problem solving. Columns 3 and 4 present estimates for workers in industries at the lowest and highest terciles of innovative intensity. Columns 5 and 6 present estimates for workers in industries requiring low and high levels of problem solving. And Columns 


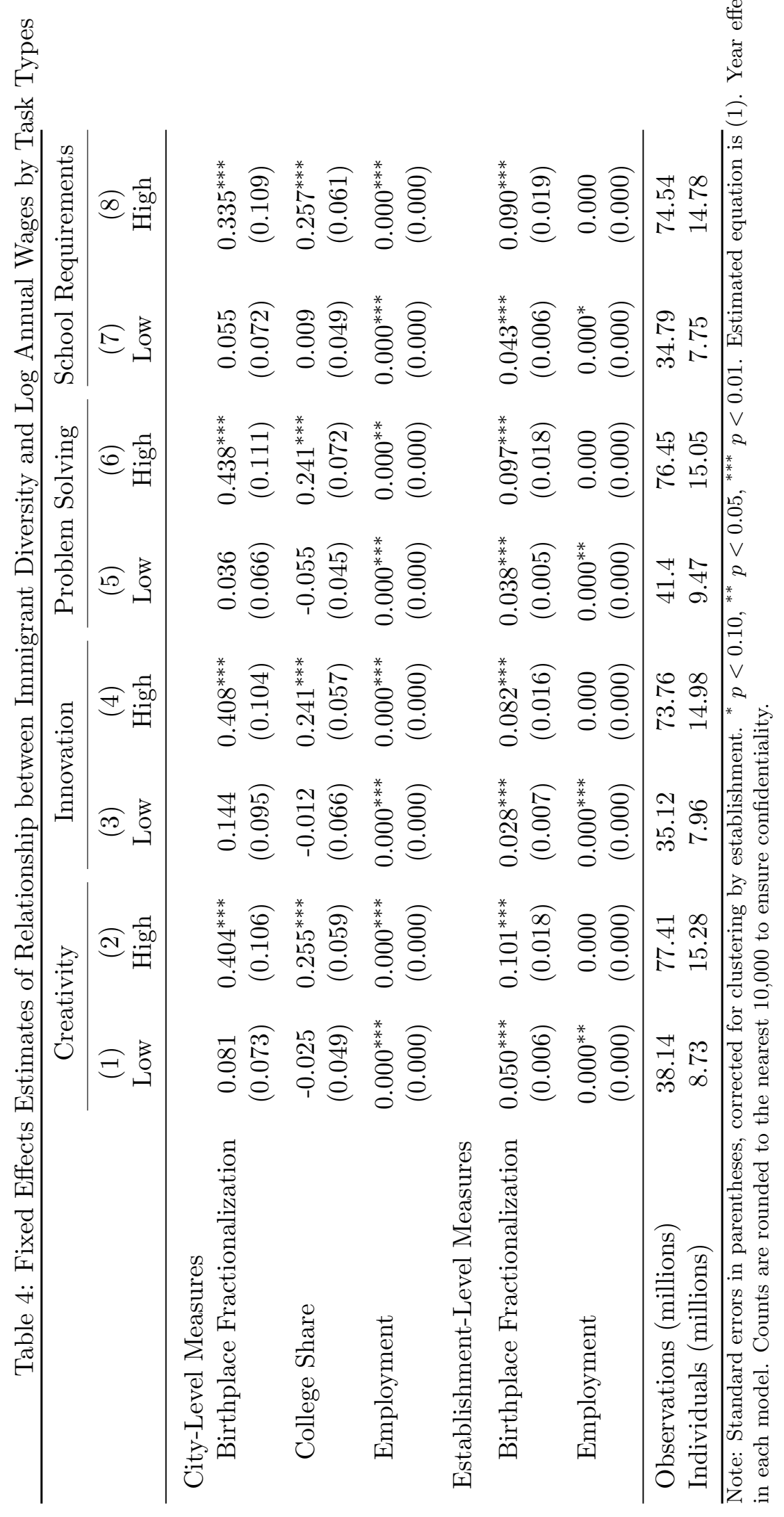


7 and 8 show results for workers in industries requiring low and high levels of required schooling. A consistent pattern is found throughout. In each pair of results, city diversity is unrelated to wages for workers in the lowest tercile, while a positive and statistically significant relationship is estimated for workers in the highest tercile. Overall, these models yield the insight that metropolitan immigrant diversity positively influences productivity in industries that prominently feature complex problem solving, whereas among workers in industries where such tasks are peripheral, diversity does not play a role in shaping productivity. This lends support to Hypothesis 1.

Interestingly, Table 4 shows that, across all of the groups, diversity measured at the establishment level is positively and significantly related to wages. Nonetheless, effect sizes are systematically related to the intensity of complex problem solving. Coefficients are uniformly larger in the highest tercile of a particular activity - at least double the size of the coefficient in the lowest tercile. In other words, although changes in the diversity found in one's work establishment appear to raise wages regardless of the kinds of activities being undertaken at work, benefits are considerably larger for workers that are more intensively engaged in complex problem solving. Though somewhat different from the city effect, this result lends further support for Hypothesis 1.

Given that interaction is the key mechanism through which diversity exerts an influence on productivity, we may gain insight into the different relationships between diversity and wages at each scale of observation by considering how interaction differs in each context. As work on segregation by Ellis et al. (2004) suggests, workplaces, unlike cities, have a certain base layer of integration - and thus interaction - built into them. For the average worker in a functioning organization, interacting with coworkers is unavoidable and essential. This minimum level of interaction may ensure that the average establishment, no matter how weakly their industry is involved in complex problem solving, benefits from internal heterogeneity. We still cannot identify the precise channel through which this effect derives. It could be that all jobs involve some kind of problems solving, complex or not, and diversity enhances this activity. Or it could be that interacting with diverse coworkers makes people happier, and so they are more productive. Or diversity among employees allows an establishment to better reach out to a diverse customer base. Whatever the channel, the guaranteed interaction in establishments is a plausible explanation for the 
persistence of this effect.

Table 5 presents estimates of Equation (1) for workers in industries that feature high and low levels of science, technology \& engineering, and math, collectively known as STEM, which are often considered to feature complex problem solving. ${ }^{7}$ Columns 1 and 2 present results for workers in top and bottom terciles of science, which we can think of as science-peripheral and science-intensive industries, respectively. Results in these columns confirm patterns seen in Table 4, whereby city-level diversity is unrelated to wages for science-peripheral workers, and positively linked to wages for science-intensive workers. Also consistent, though uniformly positive and significant, the coefficient for establishment diversity in the top science tercile is more than double the magnitude estimated for to the bottom. Similar patterns hold for estimates differentiated by math-intensity, shown in Columns 5 and 6 . Results distinguished on the basis of technology \& engineering, shown in Columns 3 and 4, are distinctive. Workers in both the lowest and highest terciles of technology \& engineering receive wage benefits from rising metropolitan immigrant diversity, but the coefficient for urban immigrant diversity among those in the highest tercile is nearly twice that of those in the lowest. Overall, this table presents findings that support those shown in Table 4. For workers in industries where STEM tasks are relatively unimportant, metropolitan immigrant diversity exerts mostly no influence on wages. In STEM-intensive industries, workers receive positive benefits from changes in diversity in their city. Across both sets of industries, diversity at the establishment level augments wages, but the size of the coefficient is again more than double among workers engaged in STEM activities.

Thus, defining complex problem solving along a wide range of related, but non-identical dimensions, spillovers from diversity tend to be, at the minimum, considerably larger for workers where complex problem solving is important. Considering immigrant diversity in cities, benefits from diversity are largely absent among workers engaged in activities in which complex problem is unimportant.

\footnotetext{
${ }^{7}$ For instance, see Hyde et al. (2008)
} 


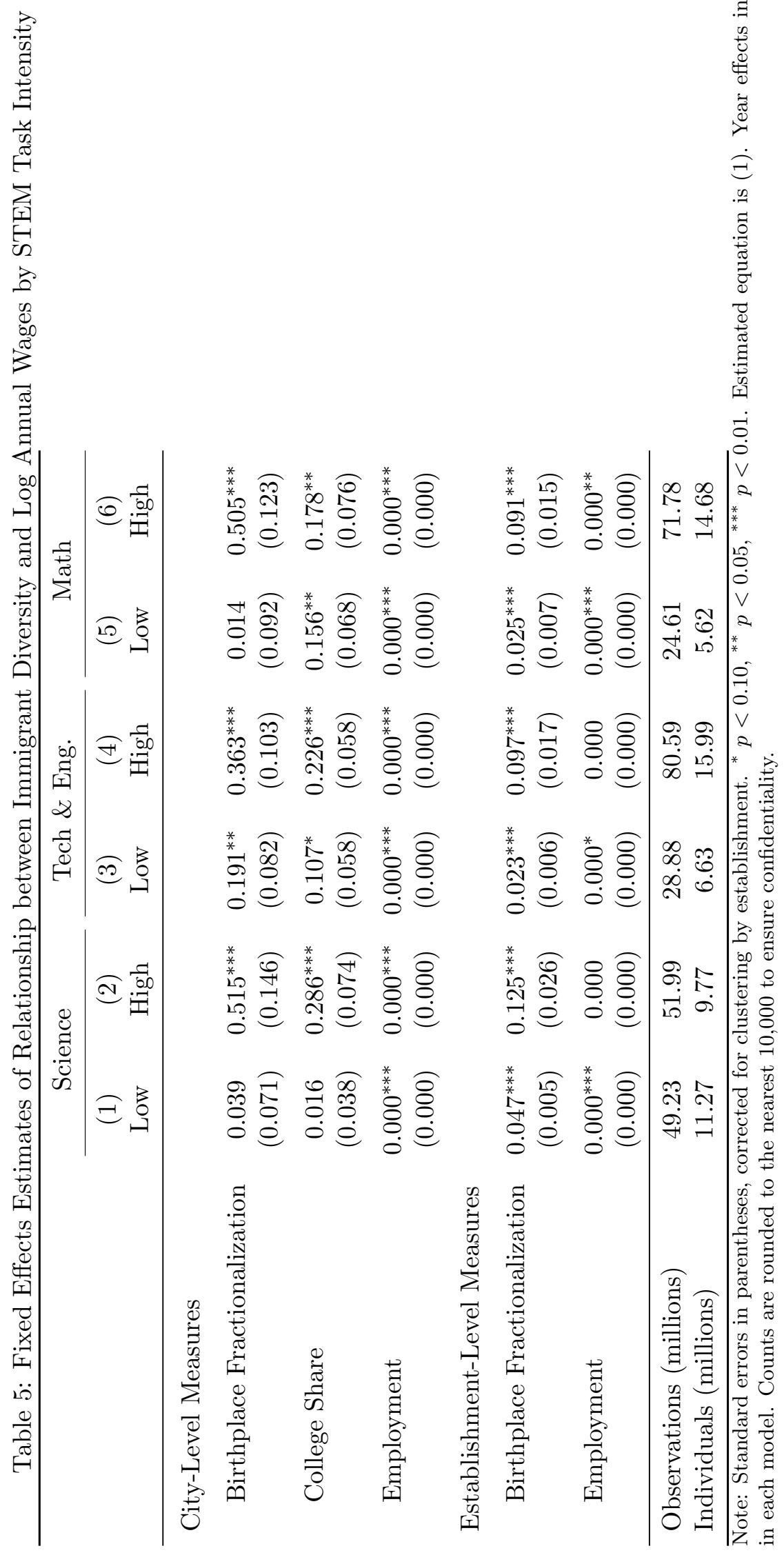




\subsection{Robustness Checks}

Equation (1) aims to address issues of worker selectivity into plants and metropolitan areas. More generally, a chief strength of the econometric approach taken is its ability to account for a wide range of sources of unobserved heterogeneity. Still, bias arising from idiosyncratic shocks occurring at the level of the city, industry, firm, or establishment could be driving the overall relationship. The paper now turns to addressing such bias by instrumenting for key explanatory variables: city and establishment diversity. Finding suitable instruments for these is challenging, and especially so at the establishment level, as LEHD offers a very limited range of plant characteristics. Candidate instruments were subjected to the usual battery of tests for exclusion, instrument strength, and (joint) orthogonality. We settled on deep lags of internal establishment and city diversity values, as well as a widely used shift-share instrument, following Card (2001). ${ }^{8}$ Using these methods, we found suitable instruments for a subset of the lowest and highest terciles of various proxies for complex problem solving. Table 6 presents results for these groups, produced using a two-step generalized method of moments (GMM) fixed effects estimator. We select cluster-robust GMM over standard two stage least squares since the nesting of individual workers inside establishments means that GMM ought to produce more efficient estimates (Baum et al., 2003). One of the ways in which using lagged internal instruments diverges from the ideal is that a good deal of observations in each group are lost; for example, a four year lag would automatically drop any of our individuals with job spells starting in the first four years and not lasting beyond the fifth year. Still, across all groups for which we have valid instruments, samples still number in the millions of observations.

Results shown in Table 6 represent IV-estimate corollaries for the estimates found in Tables 4 and 5, however, Table 6 includes only lowest and highest tercile pairs for which suitable instruments could be found. For these groups, Kleibergen-Paap underidentification tests are passed, indicating the instruments can not be considered weak. As the

\footnotetext{
${ }^{8}$ Rejected candidate instruments include a measure of the proportion of refugees settled in a metropolitan areas in the overall population, drawn from The Refugee Processing Center, part of the U.S Department of State. A wide range of 'internal' lagged instruments were explored until suitable combinations were found. Because these are lags of potentially endogenous regressors, we were especially concerned that instruments may directly influence the dependent variable, instead of influencing wages exclusively through current-year diversity levels. Indeed, exclusion tests revealed this to be a problem, especially for shallower lags. All the instruments used in the presented models did not emerge as independently significant predictors of the outcome of interest, therefore providing support for their use.
} 


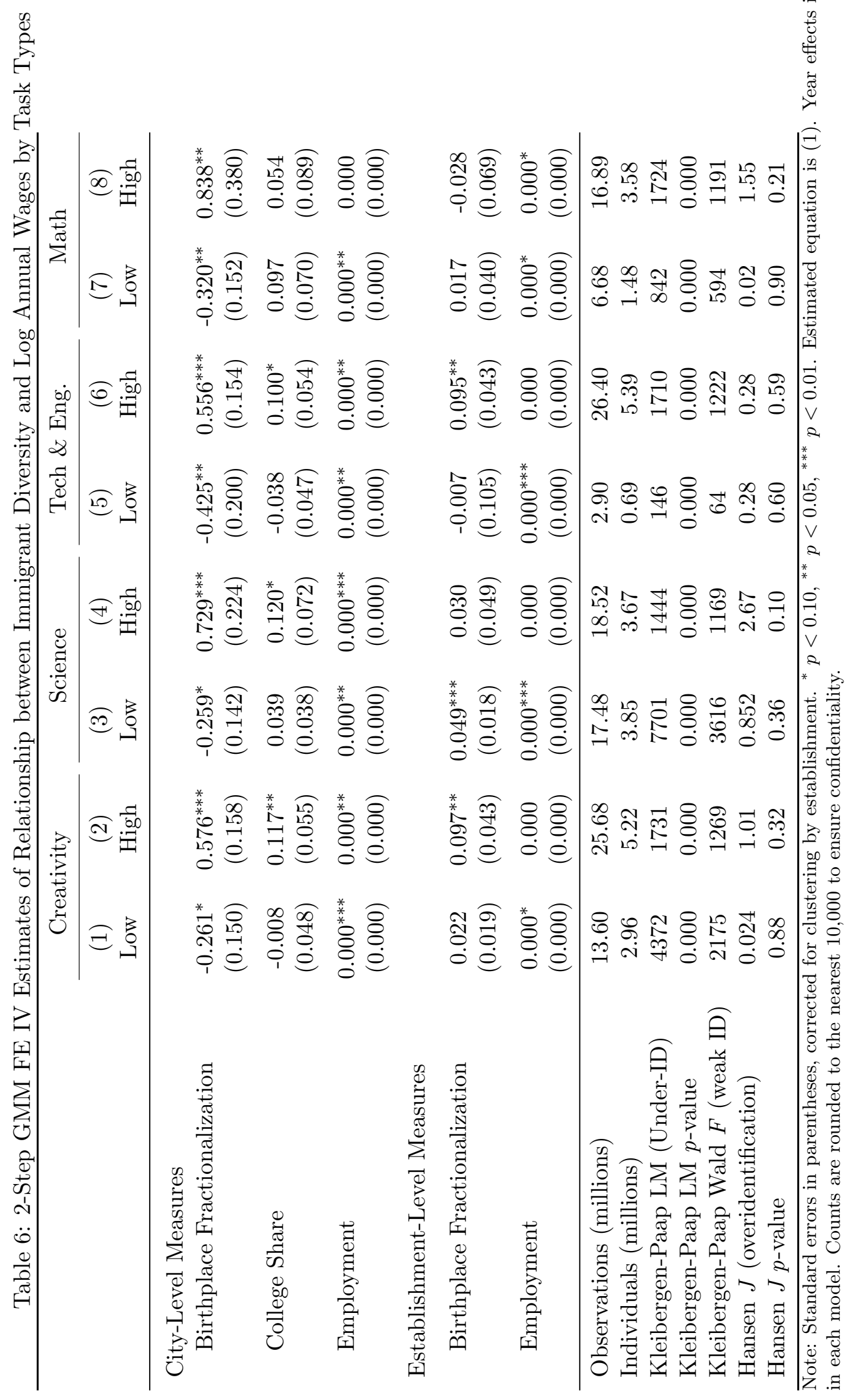


estimating equation is overidentified, we test for the joint orthogonality of the excluded instruments, using the Hansen $J$ test statistic; results suggest that the instruments are distributed independently of the error process and that they are properly excluded from the model. Table 6 produces results that differ somewhat from the non-instrumented estimates. In the lowest tercile of each complex problem solving indicator, the coefficient on city level diversity is negative and signficant, though at a low threshold for some groups: for creativity (Column 1) and science (Column 3) the coefficient is significant at only the ten percent level; technology and engineering (Column 5) and math (Column 7) are significant at a five percent level. This represents a modest departure from the previous results, but not one that is incompatible with the intuition expressed in Hypothesis 1. Instrumented results for workers in the highest tercile of the various proxies for complex problem solving hew closer to uninstrumented estimates. Here the coefficients for city-level diversity are uniformly positive and signficant, most at a one percent level. The main difference of note is that the coefficients are larger that those presented in Tables 4 and 5 . At the establishment level, the results differ somewhat. Only three of the eight groups have a significant coefficient at the establishment level, and these represent an idiosyncratic group: the highest tercile of creativity (Column 2), the lowest tercile of science (Column 3), and highest tercile of technology and engineering (Column 6).

There are a few reasons to interpret the details of Table 6 with some caution. One reason is that, in general, IV generates less efficient estimates. Second, as noted, the lags involved in passing instrument tests mean that many observations are lost, further affecting precision, and shortening job spells over which to estimate the relationships of interest. Last, given the challenges of finding suitable instruments, we are unable to present the full range of measures capturing complex problem solving. Those caveats notwithstanding, the IV results support a clear contrast between city diversity effects felt among workers engaged in activities that differently feature complex problem solving, conforming to both theoretical priors and uninstrumented results. Workers intensively engaged in complex problem solving receive benefits from rising city diversity, one that is much larger than that experienced by workers in the lowest terciles across different complex problem solving measures. Though it would be possible to see the significant negative effect for workers in the lowest tercile of complex problem solving as evidence of 
the more negative theoretical effects of diversity, we remain hesitant to push this very far due to potential imprecision. Instead we prefer to focus on the contrast between the low and high groups as the more important story from these results. The GMM results offer less clear support for the interpretation of the links between diversity at the establishment level and wages. However, since prior work (i.e. Kemeny and Cooke, 2015) provides broad support for this relationship across all workers in a similar IV context, it is plausible that the IV results have been biased by the constraints placed upon the sample.

\subsection{Complex Problem Solving and Interaction}

Next, we turn to the second hypothesis: that positive spillovers from diversity will be especially strong for workers engaged in high levels of both complex problem solving and interaction. We cannot directly observe interaction, but employ the $\mathrm{O}^{*} \mathrm{NET}$-derived proxy of 'social orientation' to differentiate low-and high interaction industries. The estimation approach directly follows from Equation (1), and can be interpreted in a manner consistent with results shown in Tables 4 and 5 . The key difference lies in the determination of which workers fall into which groups. All of the workers analyzed here fall into the highest tercile of the relevant proxy for complex problem solving. In Tables 7 and 8, the lowest tercile represents those that additionally fall into the lowest tercile of social orientation, while the high tercile represents those that are highest in both complex problem solving and social orientation. The former can be thought of as the 'sculptors' and the latter as 'film directors.' For instance, Columns 1 and 2 in Table 7 cover only workers in industries that fall into the highest tercile for creativity. Column 1 shows results for such workers who also fall into the lowest tercile for social orientation. Workers of this kind are employed in establishments classified in NAICS into such categories as Retailers, and Independent Artists and Writers. Column 2 presents a contrast, showing results for workers in industries that feature high levels of both creativity and social orientation. This group covers those involved in Science Research and Design Services as well as Computer Systems Design.

Column 1 in Table 7 reports the results for workers in industries that feature high creativity and low social orientation. The coefficient for city birthplace fractionalization is not significant. Column 2 presents the corresponding estimates for workers in the highcreativity, high-social-orientation group. The coefficient on city immigrant diversity is 


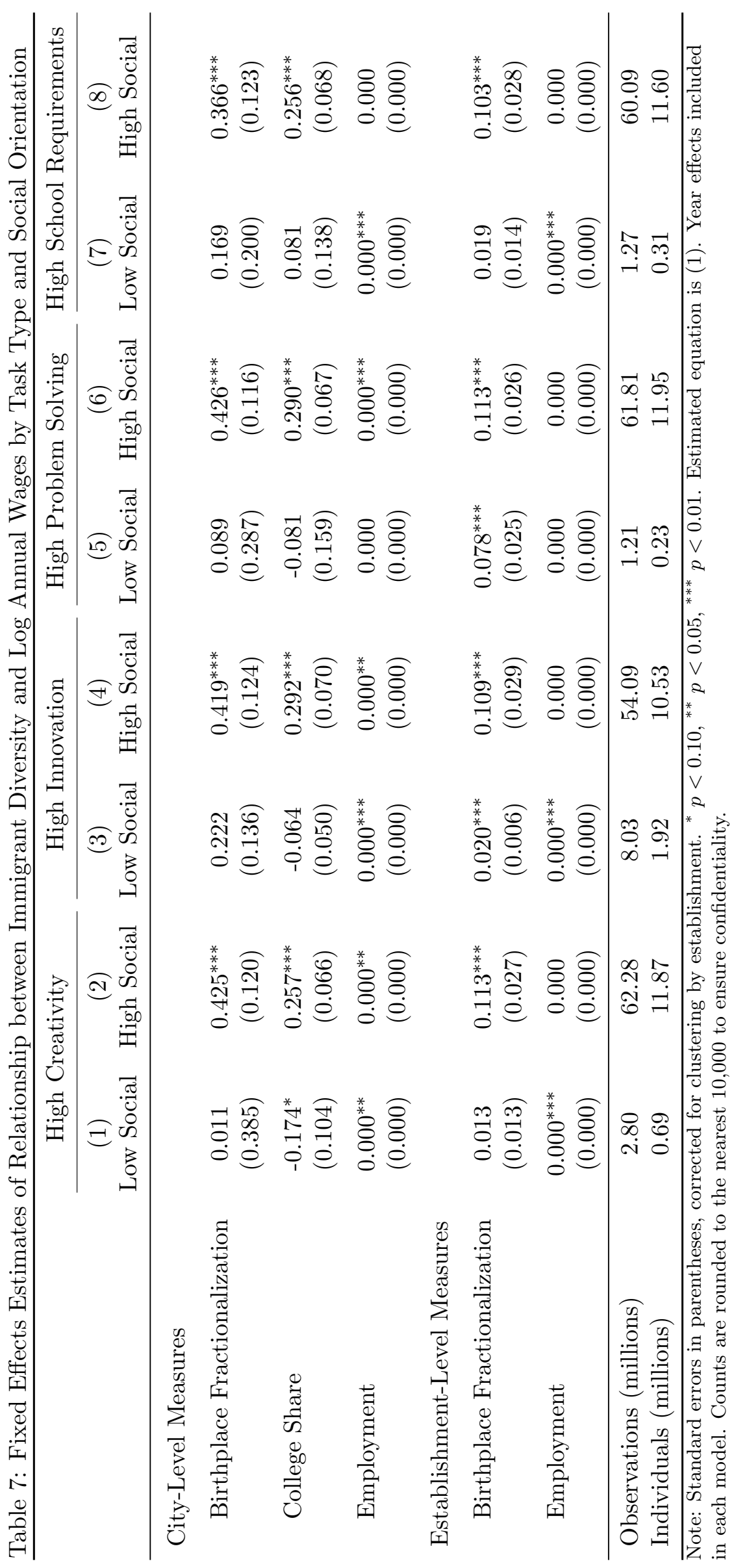


positive and statistically significant at a one percent level. This pattern of differentiation is repeated for innovation, problem solving and school requirements. The impacts of changes in urban immigrant diversity, in other words, are nonuniform even among workers whose work requires similarly high levels of complex problem solving. Within this group of workers, spillovers accrue only among those whose work is additionally intensive in social interaction - or at least the orientation towards such interaction. This confirms expectations expressed in Hypothesis 2. The pattern of benefits flowing from diversity in the workplace is also broadly supportive. In some cases (creativity in Column 1, and schooling requirements in Column 7), workers in activities that are not interaction-rich are not affected by changes in the diversity in their workplace. In others (innovation in Column 3 and problem solving in Column 5) such workers' wages are positively related to workplace diversity. But among workers in activities that involve workers with high levels of social orientation as well as high levels of complex problem solving, the coefficient on workplace immigrant diversity is uniformly positive and significant, and it is always considerably larger than the coefficient for those where interaction is less important. In short, Table 7 demonstrates a clearly differentiated relationship between diversity and wages within those engaged in complex problem solving, whether diversity is measured at the city or workplace level. In both cases, those intensively engaged in complex problem solving and social interaction receive the clearest and strongest benefits from increases in immigrant diversity.

Table 8 presents similar estimates, this time using measures of STEM intensity as proxies for complex problem solving. Results for these measures tell a less consistent story. Considering workers in science-intensive industries, city diversity coefficients for those at either end of the spectrum of social interaction are positive and significant. Curiously, the coefficient for those at low-levels of social orientation is considerably larger than those that are more socially oriented. One caveat is that the sample for workers at low levels is small by the standards of other estimates presented in this paper. For workers intensively involved in engineering and technology (Columns 3 and 4), coefficients for those in the lowest and highest terciles of social orientation are positive and significant. This time, though, the value estimated for workers in the highest tercile of social orientation is larger than for those in the lowest. Columns 5 and 6 present estimates for workers in math- 
intensive activities. Results here closely resemble those in the previous table: no significant relationship is found for those in the lowest tercile of social orientation, while a positive and significant relationship is found for those in the highest tercile of social orientation. Coefficients for workplace diversity resemble those presented in the previous table: for workers in high-complex problem solving activities but with low levels of social orientation, coefficients are either insignificant or much smaller than for those with high levels of social orientation. Among those with high social orientation, establishment immigrant diversity is consistently positive and significantly related to wages.

\section{Conclusion}

This paper set out to 'stress test' the theory underlying a raft of recent papers exploring the relationship between immigrant diversity and productivity. This growing body of work, connected to deeper traditions in regional science, management and organizational sociology, considers that the productivity impacts of diversity are manifested through the channel of interpersonal interaction. Interaction among heterogeneous agents is believed to improve complex problem solving, but the extant urban-focused research explores diversity impacts without differentiating among workers on the basis of the kind of work in which they are engaged. As a consequence, theory and empirics remain at some remove.

This paper takes a first step toward bringing them closer together. Two hypotheses are tested. The first considers that diversity impacts ought to be more strongly felt among workers that are intensively involved in various forms of complex problem solving. The second hypothesis suggests that, among such workers, those who are additionally oriented toward social interaction ought to be particularly enriched by the diversity in their midst.

In addition to the novelty of these hypotheses (especially in the urban context), we add value in a few important ways. First, we employ an empirical strategy that strongly addresses various factors that can bias estimates of diversity's influence. Our approach addresses bias from a geographical process of sorting on unobservables, as well as from a wide range of other sources of unobserved heterogeneity. Second, we leverage matched employer-employee data that permits consideration of the impacts of changes in diversity in cities in which individual live as well as in the establishments in which they work. Third, 


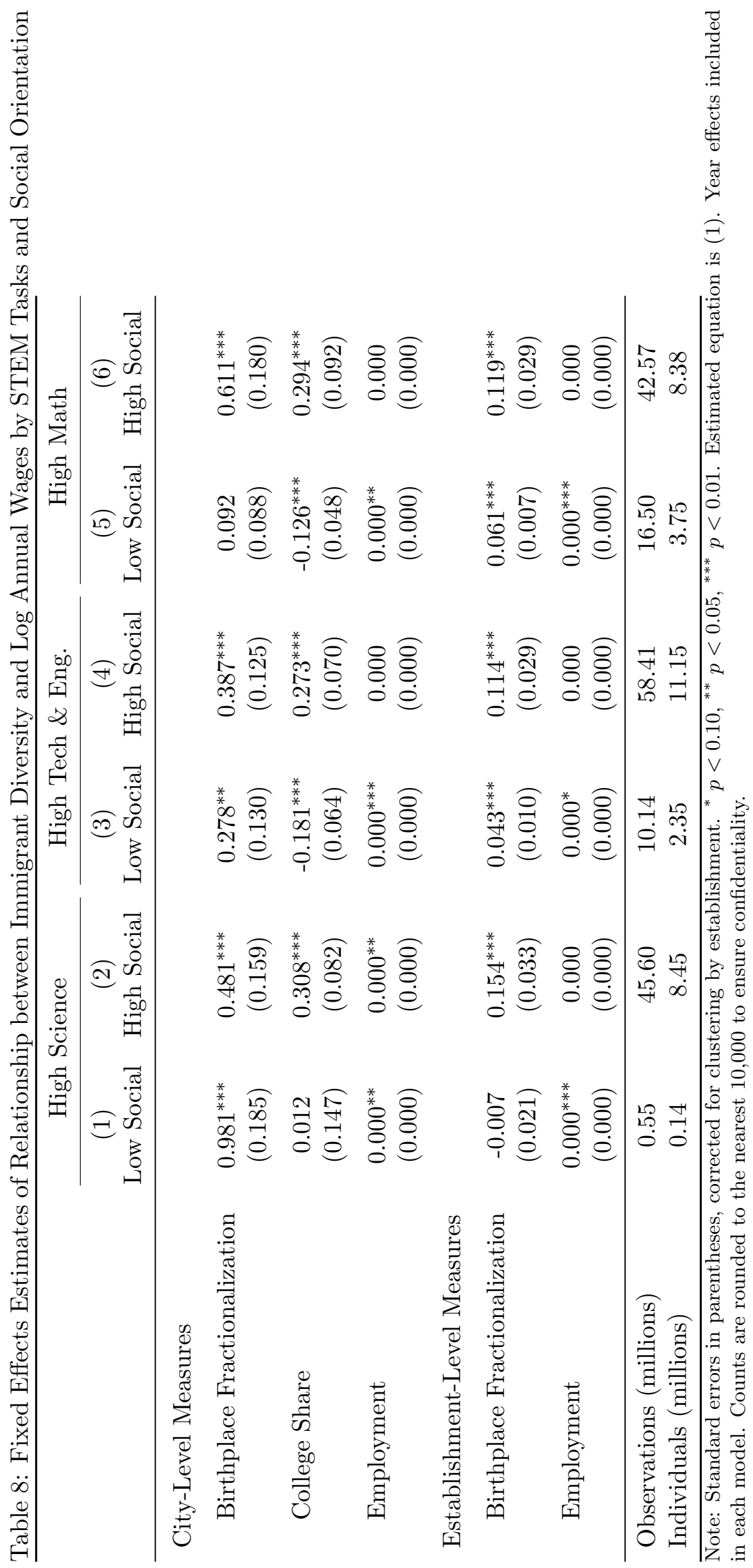


our dataset is comprehensive, covering close to the population of workers and firms in a large number of American metropolitan areas. Fourth, we consider a very wide range of proxies for complex problem solving, letting us observe consistency as well as variation across different dimensions of this latent variable.

Results shown in this paper strongly support both hypotheses. We find that workers involved in activities that intensively feature creativity, innovation, problem solving, schooling, science, engineering and technology, and mathematics are all rewarded from rising metropolitan as well as workplace immigrant diversity. Those employed in sectors featuring the lowest levels of such characteristics are either not affected by diversity, or they receive much smaller diversity benefits. Results aiming to address remaining sources of bias from endogeneity broadly support these findings, at least in terms of diversity at the city level. Additionally, we find that the strong benefits found for those workers engaged in complex problem solving are chiefly concentrated among those workers who are additionally in activities where social orientation is important. Considering workers at the highest tercile of creativity, innovation, problem solving, schooling and mathematics, only those with high levels of social orientation gain from diversity. Along the axes of science, engineering and technology, workers are rewarded at both high and low levels of social orientation.

These results add richness to existing work on diversity in both urban and organizational contexts by showing that effects are strongly differentiated according to the kinds of tasks in which workers are engaged. Given criticism suggesting that existing research remains distant from the actual mechanisms through which diversity may influence productivity (Kemeny, 2014), the present paper also contributes by providing support for the underlying theory motivating this body of empirical research.

They also offer practical significance when thinking about the economic implications of immigration, both at a regional scale and within individual organizations. Heterogeneity in place of birth offers concrete economic benefits, augmenting organizational competitiveness as well as regional vibrancy. This paper has helped to map out the specific contexts in which this is true, confirming that immigrant diversity's impacts are most strongly felt among workers engaged in complex problem solving, broadly conceived. 


\section{Acknowledgments}

We thank Olmo Silva, Max Nathan, and seminar participants at Oxford and Stanford for helpful discussions and suggestions. We are grateful to Bert Grider for help with disclosure avoidance review. This work has been supported by U.S. National Science Foundation grant BCS-1359768. The research uses data from the Census Bureau's Longitudinal Employer Household Dynamics Program, which was partially supported by the following National Science Foundation Grants SES-9978093, SES-0339191 and ITR-0427889; National Institute on Aging Grant AG018854; and grants from the Alfred P. Sloan Foundation. 


\section{References}

Acemoglu, D. and Angrist, J. (2001). How large are human-capital externalities? evidence from compulsory-schooling laws. In NBER Macroeconomics Annual 2000, Volume 15, pages 9-74. MIT Press.

Ager, P. and Brückner, M. (2013). Cultural diversity and economic growth: Evidence from the US during the age of mass migration. European Economic Review, 64:76-97.

Aiken, M. and Hage, J. (1971). The organic organization and innovation. Sociology, $5(1): 63-82$.

Auh, S. and Menguc, B. (2005). Top managemetn team diversity and innovativeness: The moderating role of interfunctional coordination. Industrial Marketing Management, 34:249-261.

Bakens, J., Mulder, P., and Nijkamp, P. (2013). Economic impacts of cultural diversity in the Netherlands: Productivity, utlility and sorting. Journal of Regional Science, $53(1): 8-36$.

Baum, C. F., Schaffer, M. E., Stillman, S., et al. (2003). Instrumental variables and gmm: Estimation and testing. Stata journal, 3(1):1-31.

Bellini, E., Ottaviano, G., Pinelli, D., and Prarolo, G. (2013). Cultural diversity and economic performance: Evidence from European regions. In Crescenzi, R. and Percoco, M., editors, Geography, institutions and regional economic performance, pages 121-142. Springer-Verlag.

Card, D. (2001). Immigrant inflows, native outflows, and the local labor market impacts of higher immigration. Journal of Labor Economics, 19(1):22-64.

Clearwater, S., Huberman, B., and Hogg, T. (1991). Cooperative solution of constraint satisfaction problems. Science, 254(5035):1181-1183.

Easterly, W. and Levine, R. (1997). Africa's growth tragedy: Policies and ethnic divisions. Quarterly Journal of Economics, 112(4):1203-1250.

Ellis, M., Wright, R., and Parks, V. (2004). Work together, live apart? geographies of racial and ethnic segregation at home and at work. Annals of the Association of American Geographers, 94(3):620-637.

Faems, D. and Subramanian, A. M. (2013). R\&d manpower and technological performance: The impact of demographic and task-related diversity. Research Policy, 42(9):1624-1633.

Feldman, M. P. and Audretsch, D. B. (1999). Innovation in cities: Science-based diversity, specialization and localized competition. European Economic Review, 43(2):409-429.

Fujita, M. and Thisse, J.-F. (2013). Economics of agglomeration: cities, industrial location, and globalization. Cambridge university press.

Gagliardi, L. (2014). Does skilled migration foster innovative performance? Evidence from British local areas. Papers in Regional Science. 
Gibbons, S., Silva, O., and Weinhardt, F. (2013). Everybody needs good neighbours? evidence from students' outcomes in England. The Economic Journal, 123(571):831874.

Harrison, D. A. and Klein, K. J. (2007). What's the difference? diversity constructs as separation, variety, or disparity in organizations. Academy of Management Review, 32(4):1199-1228.

Hong, L. and Page, S. (2001). Problem solving by heterogeneous agents. Journal of Economic Theory, 97(1):123-163.

Hong, L. and Page, S. (2004). Groups of diverse problem solvers can outperform groups of high-ability problem solvers. Proceedings of the National Academy of Sciences of the United States of America, 101(46):16385-16389.

Huberman, B. (1990). The performance of cooperative processes. Physica D: Nonlinear Phenomena, 42(1):38-47.

Hyde, J. S., Lindberg, S. M., Linn, M. C., Ellis, A. B., and Williams, C. C. (2008). Gender similarities characterize math performance. Science, 321(5888):494-495.

Ibert, O. and Müller, F. C. (2015). Network dynamics in constellations of cultural differences: Relational distance in innovation processes in legal services and biotechnology. Research Policy, 44(1):181-194.

Kemeny, T. (2012). Cultural diversity, institutions, and urban economic performance. Environment and Planning A, 44(9):2134-2152.

Kemeny, T. (2014). Immigrant diversity and economic performance in cities. International Regional Science Review, doi: 10.1177/0160017614541695.

Kemeny, T. and Cooke, A. (2015). Spillovers from immigrant diversity in cities. Working Papers 15-37, Center for Economic Studies, U.S. Census Bureau.

Knack, S. and Keefer, P. (1997). Does Social Capital Have An Economic Payoff? A Cross-Country Investigation. Quarterly Journal of Economics, 112(4):1251-1288.

Lee, N. (2014). Migrant and ethnic diversity, cities and innovation: Firm effects or city effects? Journal of Economic Geography, page lbu032.

Longhi, S. (2013). Impact of cultural diversity on wages, evidence from panel data. Regional Science and Urban Economics, 43(5):797-807.

Maré, D. C., Fabling, R., and Stillman, S. (2014). Innovation and the local workforce. Papers in Regional Science, 93(1):183-201.

Marshall, A. (1890). Principles of Economics. Macmillan, London, 8th edition.

McKinney, K. and Vilhuber, L. (2011). LEHD data documentation LEHD-OVERVIEWS2008-rev1. U.S. Census Bureau Center for Economic Studies Working Paper 11-43.

Moretti, E. (2004a). Estimating the social return to higher education: evidence from longitudinal and repeated cross-sectional data. Journal of Econometrics, 121(1-2):175212. 
Moretti, E. (2004b). Human capital externalities in cities. Handbook of regional and urban economics, 4:2243-2291.

Nathan, M. (2011). The long term impacts of migration in British cities: Diversity, wages, employment and prices. LSE Spatial Economics Research Centre (SERC) Discussion Paper 67.

Nathan, M. (2014). The wider economic impacts of high-skilled migrants: a survey of the literature for receiving countries. IZA Journal of Migration, 3(1):4.

Nathan, M. (2015). Ethnic diversity and business performance and location: Which firms? which cities? Mimeo.

Nisbett, R., Ross, L., et al. (1980). Human inference: Strategies and shortcomings of social judgment. Prentice-Hall Englewood Cliffs, NJ.

Østergaard, C. and Timmermans, B. (2015). Diversity and innovation: The link between regional labor market characteristics, firm's employee diversity, and their innovative capabilities. Mimeo.

Østergaard, C. R., Timmermans, B., and Kristinsson, K. (2011). Does a different view create something new? the effect of employee diversity on innovation. Research Policy, 40(3):500-509.

Ottaviano, G. and Peri, G. (2006). The economic value of cultural diversity: Evidence from US cities. Journal of Economic Geography, 6(1):9.

Ozgen, C., Nijkamp, P., and Poot, J. (2013a). The impact of cultural diversity on firm innovation: evidence from Dutch micro-data. IZA Journal of Migration, 2(1):18.

Ozgen, C., Nijkamp, P., and Poot, J. (2013b). Measuring cultural diversity and its impact on innovation: Longitudinal evidence from dutch firms. Technical report, Discussion Paper Series, Forschungsinstitut zur Zukunft der Arbeit.

Parrotta, P., Pozzoli, D., and Pytlikova, M. (2014). The nexus between labor diversity and firm's innovation. Journal of Population Economics, 27(2):303-364.

Rauch, J. (1993). Productivity gains from geographic concentration of human capital: Evidence from the cities. Journal of Urban Economics, 34(3):380-400.

Ruggles, S., Alexander, J., Genadek, K., Goeken, R., Schroeder, M., and M., S. (2010). Integrated public use microdata series: Version 5.0. Technical report, Minneapolis, MN: Minnesota Population Center.

Sparber, C. (2010). Racial diversity and aggregate productivity in US industries: 19802000. Southern Economic Journal, 75(3):829.

Suedekum, J., Wolf, K., and Blien, U. (2014). Cultural diversity and local labour markets. Regional Studies, 48(1):173-191.

Tajfel, H. (1974). Social identity and intergroup behaviour. Social Science Information, 13(2):65-93.

Talke, K., Salomo, S., and Rost, K. (2010). How top management team diversity affects innovativeness and performance via the strategic choice to focus on innovation fields. Research Policy, 39(7):907-918. 
Taylor, C. and Hudson, M. (1972). World Handbook of Political and Social Indicators. Yale University Press.

Thomas, D. and Ely, R. (1996). Making differences matter. Harvard Business Review, 74(5):79-90.

Trax, M., Brunow, S., and Suedekum, J. (2012). Cultural diversity and plant-level productivity. Centre for Research and Analysis of Migration (CReAM), Department of Economics, University College London.

Turner, J. C., Hogg, M. A., Oakes, P. J., Reicher, S. D., and Wetherell, M. S. (1987). Rediscovering the social group: A self-categorization theory. Basil Blackwell.

Van Knippenberg, D. and Schippers, M. C. (2007). Work group diversity. Annual Review of Psychology, 58:515-541.

Watson, W. E., Kumar, K., and Michaelsen, L. K. (1993). Cultural diversity's impact on interaction process and performance: Comparing homogeneous and diverse task groups. Academy of management journal, 36(3):590-602.

Weber, S. and Fujita, M. (2004). Strategic immigration policies and welfare in heterogeneous countries. Fondazione Eni Enrico Mattei Research Paper 2-04. 